\title{
High Field Accelerator Magnet R\&D in Europe
}

\author{
A. Devred, D. E. Baynham, L. Bottura, M. Chorowski, P. Fabbricatore, D. Leroy, A. den Ouden, J. M. Rifflet, \\ L. Rossi, O. Vincent-Viry, and G. Volpini
}

\begin{abstract}
The LHC magnet R\&D program has shown that the limit of NbTi technology at $1.9 \mathrm{~K}$ was in the 10-to-10.5-T range. Hence, to go beyond the $10-\mathrm{T}$ threshold, it is necessary to change the superconducting material. Given the state of the art in HTS, the only serious candidate is $\mathrm{Nb}_{3} \mathrm{Sn}$. A series of dipole magnet models built at Twente University and LBNL as well as a vigorous program carried out at Fermilab have demonstrated the feasibility of $\mathrm{Nb}_{3} \mathrm{Sn}$ magnet technology. The next step is to bring this technology to maturity, which require further conductor and conductor insulation development and a simplification of manufacturing processes. After a brief history, we review ongoing R\&D programs in Europe and we present the Next European Dipole (NED) initiative promoted by the European Steering Group on Accelerator R\&D (ESGARD).
\end{abstract}

Index Terms-Accelerator magnets, $\mathrm{LHC}$ upgrade, $\mathrm{Nb}_{3} \mathrm{Sn}$ superconductor.

\section{INTRODUCTION}

$\mathbf{T}$ HE CERN/LHC superconducting magnet R\&amp;D program was successful in developing a design suitable for industrial production [1], but it demonstrated also that the limit of accelerator magnets wound from binary NbTi conductors and operated in superfluid helium at $1.9 \mathrm{~K}$ lied in the 10-to-10.5-T range. Presently, the best performing (binary) NbTi dipole magnets are: (1) a 1-m-long, 50-mm-twin-aperture LHC model, referred to as MFISC [2]; and (2) a 1-m-long, 88-mm-single-aperture model, referred as MFRESCA [3]. MFISC was designed by a team led by D. Leroy in collaboration with the Helsinki University of Technology. It was built and cold tested at CERN and reached (in a few quenches) a record magnetic flux density of $10.53 \mathrm{~T}$ at $1.77 \mathrm{~K}$. MFRESCA was designed also by a team led by D. Leroy, but was built by HMA Power Systems in the Netherlands. It is now implemented in the CERN cable test facility and is operated routinely up to $10 \mathrm{~T}$ (note that, at this field level, the Lorentz forces developed in the MFRESCA coils are about twice those developed in regular LHC dipole magnet coils

Manuscript received October 20, 2003.

A. Devred is with CEA/DSM/DAPNIA/SACM, 91191 Gif-sur-Yvette Cedex, France. He is also with CERN/AT/MAS, CH-1211, Gevève 23, Switzerland (e-mail: arnaud.devred@cern.ch).

D. E. Baynham is with the Engineering Department, CCLRC-RAL, Chilton, Didcot, Oxon, UK, OX11 0QX.

L. Bottura, D. Leroy, L. Rossi, and O. Vincent-Viry are with CERN/AT.

M. Chorowski is with the Institute of Power Engineering and Fluid

Mechanics, Wroclaw University of Technology, 50370 Wroclaw, Poland.

P. Fabbricatore is with INFN-Genova, 16146 Genova, Italy.

A. den Ouden is with the Department of Applied Physics, University of Twente, 7500 AE Enschede, The Netherland.

J. M. Rifflet is with CEA/DSM/DAPNIA/SACM.

G. Volpini is with INFN-Milano/LASA, 20090 Segrate (Milano), Italy.

Digital Object Identifier 10.1109/TASC.2004.829121 at $8.4 \mathrm{~T}$ ). The LHC magnet results imply that in order to go beyond the 10-T threshold, it is necessary to change the superconducting material.

Ternary NbTiTa alloys have the potential to provide a small gain in field (up to $1.25 \mathrm{~T}$ at $1.8 \mathrm{~K}$ ) while keeping similar wire and identical magnet manufacturing procedures. In addition to the facts that very little R\&D has been carried on this material for the last 20 years and that the potential for increased highfield performance was never fully translated in terms of critical current density, the quench field of ternary NbTiTa magnets can be situated in the 11-to-11.5 T range, only marginally above that of present binary NbTi technology.

High Temperature Superconductors (HTS) are not yet ready for large-scale applications requiring high current densities under high magnetic fields, and it is likely that it will take at least another decade before they become competitive. In spite of a recent breakthrough in thin films [4], the upper critical field of $\mathrm{MgB}_{2}$ wires is still two low and such wires are far from being an industrial product. $\mathrm{Nb}_{3} \mathrm{Al}$ exhibits promising properties, but there are serious manufacturing issues that have yet to be resolved. It follows that the only credible candidate to open a new field range (beyond 11.5 to $12 \mathrm{~T}$ ) is $\mathrm{Nb}_{3} \mathrm{Sn}$ [5].

$\mathrm{Nb}_{3} \mathrm{Sn}$ has a critical temperature, $T_{c}$, and an upper critical field, $B_{c 2}$, that are about twice those of NbTi. However, once formed, it becomes brittle and its critical parameters $\left(T_{c}, B_{c 2}\right.$, and the critical current density, $J_{c}$ ) are strain sensitive [6]. The brittleness and strain-sensitivity of $\mathrm{Nb}_{3} \mathrm{Sn}$ require a different approach to all manufacturing processes and, so far, have limited its use to specific applications (such as insert coils for high-field NMR spectrometers).

In spite of the aforementioned difficulties, significant progress has been made over the last decade thanks to: (1) The successful manufacturing and tests of the ITER model coils, which, among other, have required the production of $\sim 30$ metric tons of $\mathrm{Nb}_{3} \mathrm{Sn}$ wires [7], [8]; (2) a US National program for the development of high-performance $\mathrm{Nb}_{3} \mathrm{Sn}$ wires, supervised by R.M. Scanlan at Lawrence Berkeley National Laboratory (LBNL), which has led already to a three-to-four-fold increase in $J_{c}$ with respect to ITER model coil specifications [9]; and (3) a series of record-breaking dipole magnet models opening the 10-to-15 T range. This magnet series include the MSUT model built at Twente University described below and three models built and cold tested at LBNL: (1) a 50-mm-aperture, $\cos \theta$ model, referred to as D20, which (after training) reached $13.5 \mathrm{~T}$ at $1.8 \mathrm{~K}$ in 1997 [10], a 25-mm-gap, racetrack-type, model, referred to as RD-3, which (after training) reached $14.7 \mathrm{~T}$ at $4.2 \mathrm{~K}$ in 2001 [11] and the recently tested H-block-type, HD-1 model, which (after training) achieved close to $16 \mathrm{~T}$ in a $20 \times$ $10 \mathrm{~mm}$ aperture [12]. 
The progress made in $\mathrm{Nb}_{3} \mathrm{Sn}$ technology let us hope that it is at hand for the next generation of high-field and high-field-gradient accelerator magnets. Looking at the prospects and time scale of High Energy Physics (HEP) projects, future needs can be inventoried as follows [13]: (1) large-aperture, high-performance dipole and quadrupole magnets to replace the present LHC Interaction Region (IR) magnets for a luminosity upgrade ( 2015) [14]; (2) high-performance, final-focusing quadrupole magnets for linear collider applications (mid 2010's); and (3) high-performance, low-cost dipole and quadrupole magnets for an LHC energy upgrade or a super-LHC (at the 2020 horizon). Although any of these applications is at least 10 years away, the long lead-time needed to bring a new technology to maturity requires that one starts working on them now.

At present, most of the resources in Europe are devoted to the construction of LHC (which is supposed to be commissioned in the Spring of 2007), and US national laboratories and wire manufacturers clearly lead the way in high-field, $\mathrm{Nb}_{3} \mathrm{Sn}$ accelerator magnet R\&D [12]. In this paper, we review the European efforts to promote $\mathrm{Nb}_{3} \mathrm{Sn}$ technology for HEP applications. After a brief history (Section II), we report on the status of ongoing programs at Twente University and CEA/Saclay (Section III), and we present the Next European Dipole (NED) initiative promoted by the European Steering Group on Accelerator R\&D (ESGARD; Section IV).

\section{BRIEF HISTORY}

\section{A. The Pioneers}

In 1981, J. Pérot at CEA/Saclay used leftover components and tooling from a previous $\mathrm{NbTi}$ dipole magnet $\mathrm{R} \& \mathrm{D}$ program for UNK to build a $0.64-\mathrm{m}$-long, $90-\mathrm{mm}$-aperture $\mathrm{Nb}_{3} \mathrm{Sn}$ dipole magnet model [15]. The magnet coils were produced according to the "wind \& react" technique and relied on a slightlykeystoned, Rutherford-type cable, made up of 23 0.7-mm-diameter, bronze-process strands produced by MCA. The model was tested in 1982 and reached a maximum field of $5.3 \mathrm{~T}$ in 3 quenches (short of its 6-T design field because of a limitation imposed by a superconducting switch implemented in the quench protection system).

At about the same time, A. Asner at CERN designed and built a 0.9-m-long, 130-mm-aperture quadrupole magnet model, referred to as SUPERCASTOR [16]. This "wind \& react" magnet relied on a original conductor manufactured by Vacuumschmelze (VAC). This conductor, shown in Fig. 1, was made up of 12 0.4-mm-diameter strands assembled around a $0.4 \times 1.5 \mathrm{~mm}^{2}$ copper strip. Two of the 12 wires were pure copper while the other 10 were niobium-bronze composites. The magnet was cold tested in 1983 and reached a maximum field gradient of $70.5 \mathrm{~T} / \mathrm{m}$ (corresponding to a 7.8-T conductor peak field) in 5 quenches.

\section{B. $R \& d$ Toward LHC}

In 1986, CERN set up a collaboration with the Austrian company ELIN to design and build a LHC-type, $\mathrm{Nb}_{3} \mathrm{Sn}$ dipole magnet model [17]. The 1-m-long, 50-mm-single-aperture model was manufactured by ELIN (according to the "wind $\&$ react" technique) and relied on bronze-process conductors

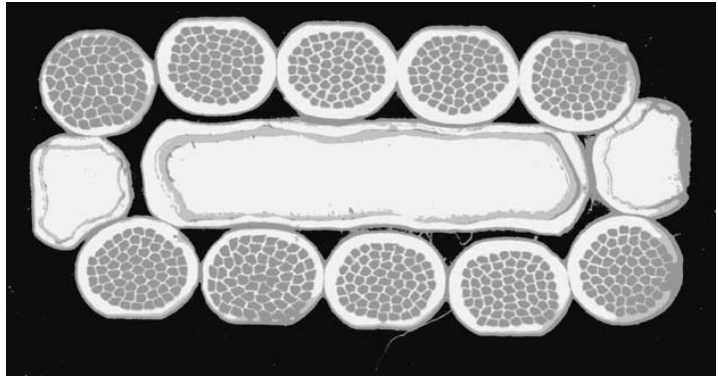

Fig. 1. Original Rutherford-type cable made up of bronze-process $\mathrm{Nb}_{3} \mathrm{Sn}$ wires mixed with pure-copper ones assembled around a thick copper core. This cable was produced by Vacuumschmelze and used at CERN in the 130-mm-aperture, 70-T/m SUPERCASTOR quadrupole magnet model.

produced by VAC. It was cold tested at CERN in June 1989 and reached $9.25 \mathrm{~T}$ in 7 quenches at $4.3 \mathrm{~K}$ [18].

The results of this program clearly showed that the bronzeprocess was too limited in terms of critical current density to suit the needs of HEP accelerator magnet applications. To address this issue, CERN decided soon after to promote the use of the innovative and promising Powder-In-Tube (PIT) conductor devised by the Energy research Center of the Netherlands (ECN) [19]. An order was placed with ECN and a magnet pole was manufactured by ELIN. This pole was cold tested in a mirror configuration at CERN in 1992.

In parallel, a collaboration, involving CERN, the Netherlands Institute for Nuclear \& High Energy Physics (NIKHEF), the Netherlands Foundation for Fundamental Research in Matter (FOM) and the University of Twente, launched in 1989 a program to design and build a high-field, $\mathrm{Nb}_{3} \mathrm{Sn}$ dipole magnet model. This program led to the manufacturing, at Twente University, of a 1-m-long, 50-mm-single-aperture dipole magnet, referred to as MSUT. MSUT relied on PIT conductors produced by ECN. It was cold tested at CERN, a first time in 1995, when it reached a record field of $11.03 \mathrm{~T}$ on its first quench at $4.4 \mathrm{~K}$ [20]. It was retested in 1997, again at $4.4 \mathrm{~K}$, and achieved a maximum field of $11.3 \mathrm{~T}$ in five quenches [21].

\section{Other Efforts}

From 1994 through 1998, a team of INFN-Milano/LASA led by L. Rossi investigated various designs of large-aperture, highfield-gradient $\mathrm{Nb}_{3} \mathrm{Sn}$ quadrupole magnets for LHC Interaction Regions and sub-contracted Europe Metalli to develop highperformance, internal-tin $\mathrm{Nb}_{3} \mathrm{Sn}$ wires [22]. The INFN/Europa Metalli program culminated in 1998 with the production of a ternary $(\mathrm{NbTi})_{3} \mathrm{Sn}$ wire that achieved a record non- $\mathrm{Cu} J_{c}$ of $1975 \mathrm{~A} / \mathrm{mm}^{2}$ at $4.2 \mathrm{~K}$ and 12 -T with an effective filament diameter of $\sim 100 \mu \mathrm{m}$ [23]. Unfortunately, Europa Metalli stopped soon after the production of this type of wire.

\section{ONGOING PROGRAMS}

\section{A. Wire Development}

1) Pit-Process at SMI: In 1994, ShapeMetal Innovation (SMI) took over the manufacturing and development of the PIT-conductor from ECN. SMI has succeeded in developing both high-strength conductors for high-field NMR applications and high-current-density wires with small filaments for 


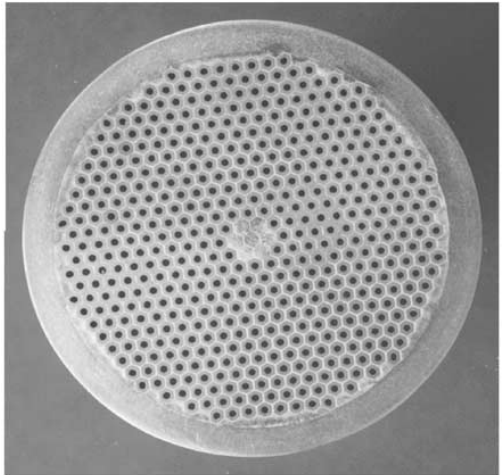

(a)

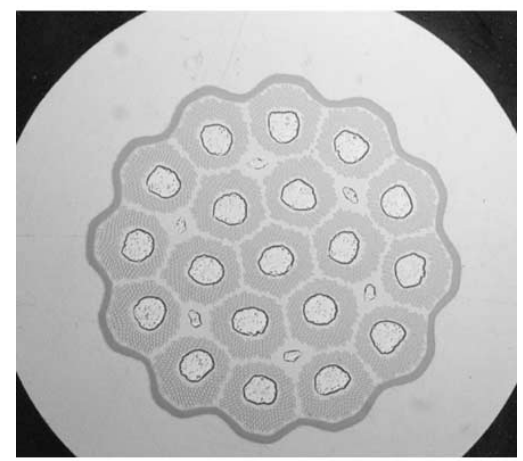

(b)

Fig. 2. Examples of $\mathrm{Nb}_{3} \mathrm{Sn}$ wires developed in Europe for HEP applications (a) binary- $\mathrm{Nb}_{3} \mathrm{Sn}$ PIT wire produced by SMI (top); (b) ternary-(NbTa) ${ }_{3} \mathrm{Sn}$ internal-tin wires produced by Alstom/MSA (bottom). Both wires have 18-to-20 $\mu \mathrm{m}$ effective filament diameters.

accelerator magnet applications [24]. In the framework of the development of a large-bore, 10-T dipole magnet (see Section III-B-1), a binary- $\mathrm{Nb}_{3} \mathrm{Sn}$ PIT wire with $20 \mu \mathrm{m}$ filaments and a non- $\mathrm{Cu} J_{c}$ of $2200 \mathrm{~A} / \mathrm{mm}^{2}$ at $4.2 \mathrm{~K}$ and $10 \mathrm{~T}$ has been successfully manufactured. As a result of the same program a ternary-(NbTa $)_{3} \mathrm{Sn}$ PIT wire with $40 \mu \mathrm{m}$ filaments and a non- $\mathrm{Cu} J_{c}$ of $2500 \mathrm{~A} / \mathrm{mm}^{2}$ at $4.2 \mathrm{~K}$ and $12 \mathrm{~T}$ has been developed and is currently manufactured in 500-1000 meter unit lengths for both EU and US accelerator magnet programs. Fig. 2(a) presents a cross-sectional view of the binary wire.

2) Internal-Tin Process at Alstom/MSA: In 1996, CEA/Saclay set up a collaboration with Alstom/MSA to develop an internal-tin, ternary $(\mathrm{NbTa})_{3} \mathrm{Sn}$ wire responding to ITER HPI specifications and to put this wire into practice by building a quadrupole magnet model based on the existing LHC arc quadrupole magnet design (see Section III-B-2). Alstom/MSA completed successfully its task in 1999 and was able to manufacture a wire with a non- $\mathrm{Cu} J_{c}$ of $750 \mathrm{~A} / \mathrm{mm}^{2}$ at $4.2 \mathrm{~K}$ and $12 \mathrm{~T}$ and an effective filament diameter of $18 \mu \mathrm{m}$ [25]. This wire is illustrated in Fig. 2(b).

In 2000, CEA/Saclay and Alstom/MSA signed a second collaboration agreement for the development of a more ambitious, internal-tin wire, with a noncopper critical current density of $2000 \mathrm{~A} / \mathrm{mm}^{2}$ at $4.2 \mathrm{~K}$ and $12 \mathrm{~T}$. Such wire could be used to manufacture a second quadrupole magnet model according to the specifications of the final focusing quadrupole magnets

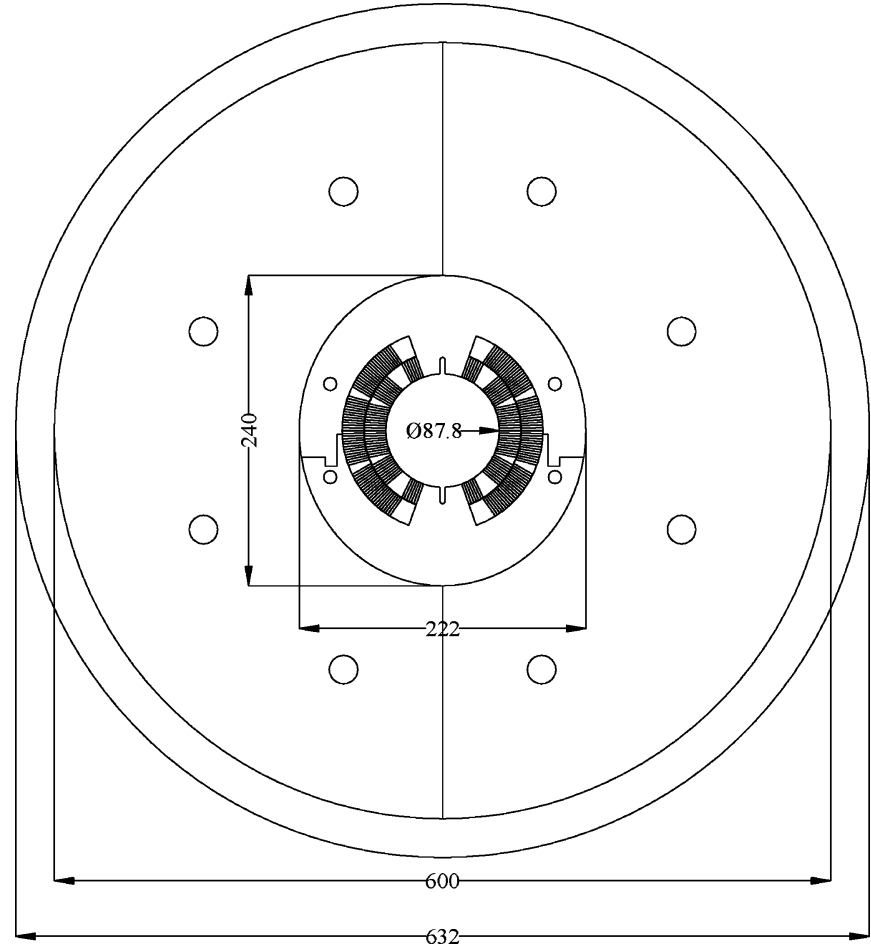

Fig. 3. Cross-sectional view of 88-mm-aperture, $10-\mathrm{T} \mathrm{Nb}_{3} \mathrm{Sn}$ dipole magnet model under development at Twente University.

presently included in the TESLA Technical Design Report. This program is still ongoing.

\section{B. Magnet $R \& D$}

1) At Twente University: Following the success of MSUT, CERN decided to renew its collaboration agreement with Twente University in 1998, with the goal of designing and building a 1-m-long, 88-mm-aperture $\mathrm{Nb}_{3} \mathrm{Sn}$ dipole magnet model delivering a nominal field of $10 \mathrm{~T}$ [26]. Such a magnet could be used to replace advantageously the low-field (4.5-T) D1 dipole magnets used to separate the colliding beams in the crowded LHC IR's [27]. (Note that the parameters of this magnet were chosen so as replace the existing D1 magnet while keeping the present IR optics and without referring to any specific IR or luminosity upgrade scenario, Fig. 3.)

The Twente program focuses on approaching field quality accelerator specifications by the development of both small-filament, binary- $\mathrm{Nb}_{3} \mathrm{Sn}$ PIT wires with a moderate current density (see Section III-A-1) and a Rutherford-type cable with controlled values of transverse and adjacent inter-strand resistances. By now, 3/4 of the wires and one (out of four) cable unit length have been produced, and a fully-equipped dummy pole has been manufactured [28]. Coil winding is tentatively scheduled to start in May 2004 and the magnet is expected to be ready for cold test 6 to 8 months later.

2) At CEA/Saclay: The main goal of the CEA/Saclay program is to get re-acquainted with $\mathrm{Nb}_{3} \mathrm{Sn}$ technology by building a 1-m-long, 56-mm-aperture quadrupole magnet model. The model relies on the same coil geometry as the 


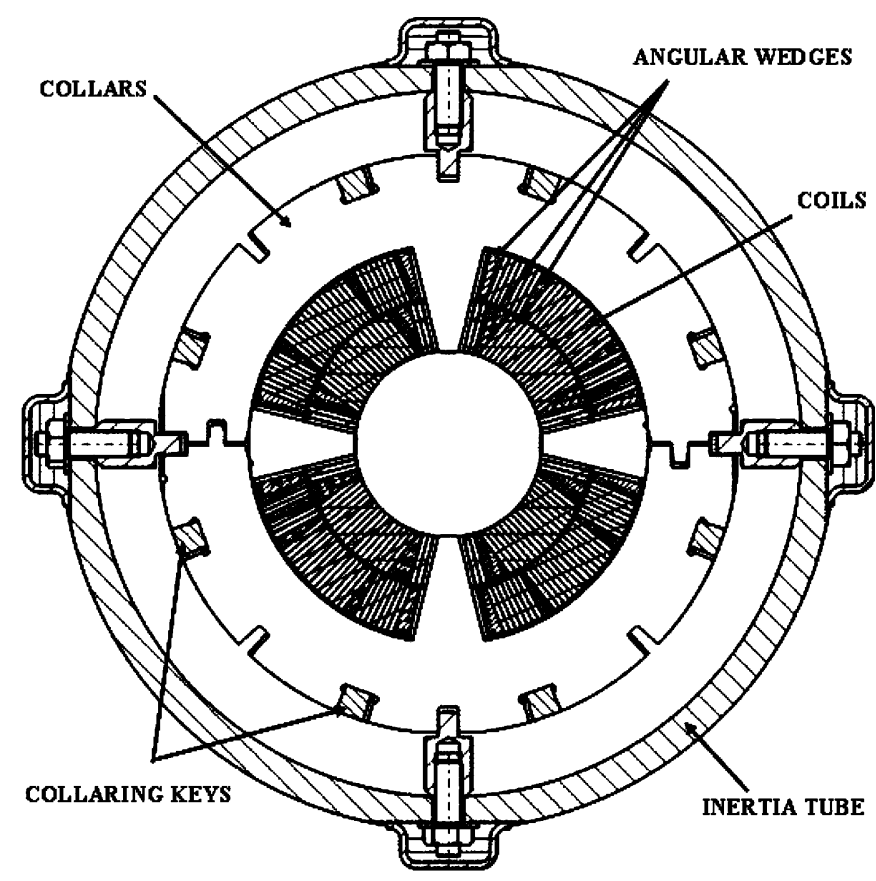

Fig. 4. Cross-sectional view of 56-mm-aperture, $210-\mathrm{T} / \mathrm{m} \mathrm{Nb}_{3} \mathrm{Sn}$ quadrupole magnet model under development at CEA/Saclay.

LHC arc quadrupole magnets, but has no iron yoke [29]. It will produce a field gradient of $211 \mathrm{~T} / \mathrm{m}$ at $11870 \mathrm{~A}$ (Fig. 4).

As of today, the main design choices have been made and the procurement of the main parts has started [30]. About $60 \%$ of the manufacturing drawings are completed and more than $50 \%$ of the budget is engaged. Test cables for two dummy poles have been delivered as well as the first components of the winding tools. Practice winding is expected to start in December 2003 and the magnet should be ready for cold test in the spring of 2005.

In parallel, CEA/Saclay is pursuing, in collaboration with Institut Européen des Membranes (IEM) of Montpellier, France, the development of an innovative insulation scheme for "wind $\&$ react" $\mathrm{Nb}_{3} \mathrm{Sn}$ coils [31]. This insulation is based on a pre-impregnated fiber tape wrapped around the cable prior to winding and should eliminate the need for a vacuum-impregnation by epoxy resin after coil heat treatment.

\section{NED PROGRAM}

\section{A. ESGARD Initiative}

In October 2002, the European Committee for Future Accelerators (ECFA) set up the European Steering Group for Accelerator R\&D (ESGARD), chaired by R. Aleksan, CEA/Saclay, with the mandate of preparing a coherent set of bids to apply for EU funding. The first outcome of ESGARD is the Coordinated Accelerator Research in Europe (CARE) proposal of Integrated Activities (IA), which was submitted to the EU on April 15, 2003. The proposal was accepted in July 2003, after reviewing and ranking by a panel of experts across the fields of science, and is now being amended to meet the funding profile allocated by the EU. The contract is expected to be signed mid-November and the various activities it encompasses could start on January $1,2004$.
The CARE project integrates all HEP-related accelerator $\mathrm{R} \& \mathrm{D}$ in Europe and is supported by more than 100 institutes. It is made up of 3 Network Activities (linear colliders, neutrino beams and High Energy High Intensity Hadron Beams or HEHIHB) and 4 Joint Research Activities (JRA's) aimed at developing specific hardware pieces or systems. The HEHIHB network includes a work package entitled Advancements on accelerator Magnet Technology (ATM) that will be coordinated by L. Rossi (CERN), while one of the JRA's, nicknamed NED (for Next European Dipole), will focus on high-field accelerator magnet R\&D. The NED JRA will be coordinated by A. Devred (CEA/Saclay).

\section{B. NED JRA Overview}

The initial NED JRA proposal had five main objectives: (1) to revisit magnetic and mechanical designs of accelerator magnet coils made from brittle materials; (2) to address coil cooling issued under high beam losses; (3) to promote high-performance $\mathrm{Nb}_{3} \mathrm{Sn}$ wire development in collaboration with European industry; (4) to improve mechanical robustness and radiation hardness of $\mathrm{Nb}_{3} \mathrm{Sn}$ conductor insulation; and (5) to put into practice all of the above in a high field (up to $15 \mathrm{~T}$ ), large aperture (up to $88 \mathrm{~mm}$ ) dipole magnet model that pushes the technology well beyond LHC limits. The proposed dipole magnet model served two purposes: (1) assessing the feasibility of such a magnet in view of possible LHC luminosity upgrade scenarios with radically different IR optics [13], [14]; and (2) upgrading the CERN/MFRESCA cable test facility presently limited to $10 \mathrm{~T}$ (see Section I).

At the EU request, the proposal has been divided up into two Phases: Phase I covers conductor development and includes some limited studies on conductor insulation (representing about $25 \%$ of the initial program), while Phase II is devoted to the detailed design, manufacturing and test of the dipole magnet model. The funding of Phase I, which is foreseen to last $\sim 3$ years, is fully secured, while that of Phase II is still uncertain.

Six institutes have agreed to collaborate to the NED JRA: CCLRC-RAL (UK); CEA/DSM/DAPNIA (France); CERN/AT (International); INFN-Milano/LASA and-Genova (Italy); Twente University (The Netherlands); and Wroclaw University (Poland). This collaboration represents a unique and original synergy of efforts among European laboratories involved in superconducting accelerator magnet development. The EU grant amounts to about $50 \%$ of the total expected budget of Phase I, the rest of the funding being provided by the main collaborators.

\section{Phase I Outline}

The Phase I of NED is articulated around three main work packages: (1) Thermal Studies and Quench Protection (TSQP); (2) Conductor Development (CD); and (3) Insulation Development and Implementation (IDI).

1) TSQP Work Package: It will be coordinated by G. Volpini (INFN-Milano/LASA). It includes two parts: (1) quench protection studies; and (2) heat transfer measurements through $\mathrm{Nb}_{3} \mathrm{Sn}$ conductor insulation. 
Quench protection will be investigated by means of a code originally developed at LASA for studies on solenoids [32]. This code was subsequently modified to study the quench protection of the $\mathrm{Nb}_{3} \mathrm{Sn}$ quadrupole magnet model evoked in Section II-C. It implements a suitable 3-D description of the coil geometry, detailed material properties as a function of temperature and magnetic field and the anisotropic behavior of composite materials like impregnated coil blocks.

The heat transfer measurements are intended to duplicate the type of investigations carried out on NbTi conductor insulation at CEA/Saclay [33]. They will require the design and fabrication of a new cryostat that will be supervised by CEA/Saclay and Wroclaw University. The new facility will be implemented and operated at CEA/Saclay.

2) $C D$ Work Package: It will be coordinated by D. Leroy (CERN) and includes the preliminary design of a large-aperture (up to $88 \mathrm{~mm}$ ), high-field (up to $15 \mathrm{~T}$ ), $\mathrm{Nb}_{3} \mathrm{Sn}$ dipole magnet aimed at deriving meaningful conductor specifications. A first pass at such a design is presented in Section IV-D.

Of course, the core of the activity will be devoted to wire and cable development. Among the various processes to produce $\mathrm{Nb}_{3} \mathrm{Sn}$ conductors, the bronze route, which enables the achievement of fine filaments, was deemed inadequate to reach the desired high critical current densities. Within the limited funding available, it was then decided to concentrate the efforts on two routes: (1) Powder In Tube (PIT) and (2) enhanced Internal Tin (IT). During the preparation of the CARE proposal, all European wire manufacturers were contacted and asked if they were interested in participating to such a program. Three of them responded positively. Two of the companies decided to join their efforts on the PIT technology while the third one will concentrate on enhanced Internal Tin. It is worth mentioning that high current densities in the 15-T range represent a new technical challenge for the European superconductor industry, which will invest in this ambitious program. A technical specification will be written in due time. Its aim will be the industrial production of high-current density wires, with diameters in the 1.1-to-1.4-mm range and piece lengths superior to $1 \mathrm{~km}$.

The wires will be characterized by performing critical current measurements at CEA/Saclay, INFN-Milano/LASA and Twente University (following a standardized protocol) and magnetization measurements at INFN-Genova. The cable critical currents will be measured at Twente University.

3) IDI Work Package: It will be coordinated by D. E. Baynham (CCLRC-RAL). It includes two main tasks: (1) studies on conventional insulation systems, relying on ceramic or glass fiber tapes and a vacuum impregnation by epoxy resin (at CCLRC-RAL), and (2) studies on innovative insulation systems relying on pre-impregnated fiber tapes and eliminating the need for a vacuum impregnation (in continuation of the ongoing work at CEA/Saclay [31]).

\section{Very Preliminary Design Study}

Preliminary electromagnetic computations have been performed to estimate the field achievable in a large aperture of $88 \mathrm{~mm}$ (similar to that of MFRESCA). The selected structure relies on a conventional, two-layer, $\cos \theta$ distribution of high

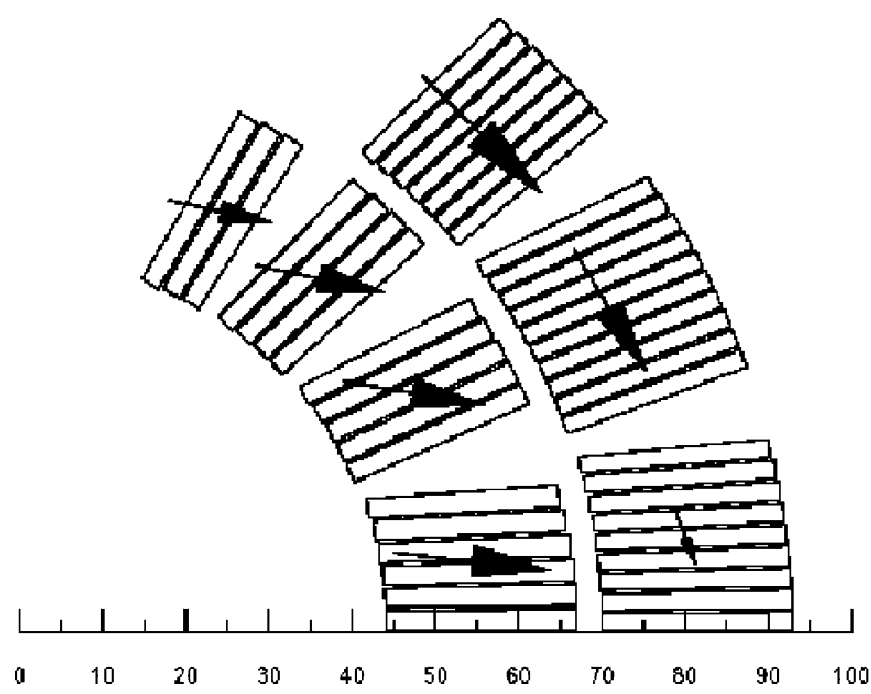

Fig. 5. Example of conductor layout optimized to produce a near $15 \mathrm{~T}$ dipole field in a $88-\mathrm{mm}$-aperture. The black arrows correspond to the average Lorentz force on each conductor block.

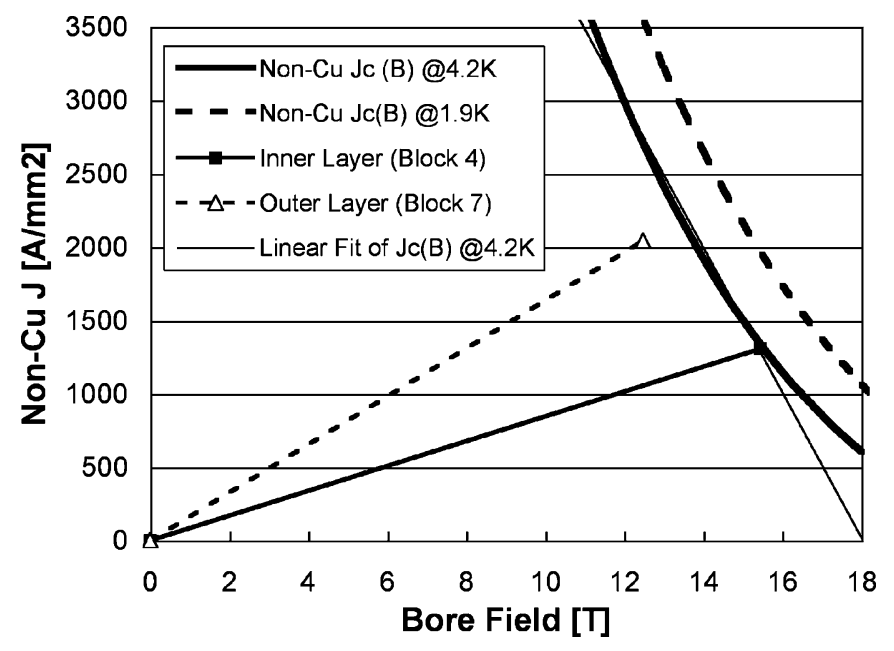

Fig. 6. Computed load lines for the conductor layout of Fig. 5 (assuming a copper-to-non copper ratio of 1.25-to-1) compared to non-Cu $J_{c}$ at $4.2 \mathrm{~K}$ and $1.8 \mathrm{~K}$ estimated from Summer's parameterization (assuming $T_{\mathrm{c} 0 \mathrm{~m}}=18 \mathrm{~K}$, $\left.B_{\mathrm{c} 20 \mathrm{~m}}=28 \mathrm{~T}, C_{0}=47310 \mathrm{AT}^{1 / 2} \mathrm{~mm}^{-2}, \varepsilon=0.25 \%\right)$.

aspect ratio cables with graded current densities. The optimization was carried out using the ROXIE software package [34]. A possible conductor layout is presented in Fig. 5, while the corresponding load lines for the inner and outer layers are shown in Fig. 6. Needless to say that these results are very preliminary and that a more thorough comparative analysis is needed and will be carried out.

Non-copper critical current densities of $3000 \mathrm{~A} / \mathrm{mm}^{2}$ at $12 \mathrm{~T}$ and $4.2 \mathrm{~K}$ have been achieved as a result of the $\mathrm{R} \& \mathrm{D}$ program carried out in the USA [9]. In the present computation, we consider a non- $\mathrm{Cu} J_{c}$ of $1500 \mathrm{~A} / \mathrm{mm}^{2}$ at $15 \mathrm{~T}$ and $4.2 \mathrm{~K}$ with a $\left(\partial J_{c} / \partial B\right)$ of $500 \mathrm{~A} / \mathrm{mm}^{2}$ between 12 and $15 \mathrm{~T}$. These high critical current density values seem a suitable target for the NED wire and cable development program. (Note that the effective filament diameter can be between 30 to $50 \mu \mathrm{m}$ since it is assumed that Ni-shims may be inserted inside the coil structure to compensate for the diamagnetic effects if a high field homogeneity is required). 
The amount of copper needed for wire stabilization and magnet protection has yet to be decided. In this preliminary optimization, we varied the $\mathrm{Cu}$-to-non- $\mathrm{Cu}$ ratio of the inner-layer wires between 1.25 to 1 and 1 to 1 , which corresponds to current densities in the Cu-part comprised between 1200 and $1350 \mathrm{~A} / \mathrm{mm}^{2}$ in the case of a quench.

The computation indicates that a field of $14.7 \mathrm{~T}$ is obtainable at $4.2 \mathrm{~K}$ for a Cu-to-non- $\mathrm{Cu}$ ratio of 1.25 . A slight decrease of this ratio enables the achievement of $14.8 \mathrm{~T}$ at $4.2 \mathrm{~K}$, while lowering the temperature down to $1.9 \mathrm{~K}$ permits to exceed $16 \mathrm{~T}$. The cables of the Fig. 5 layout are formed of a maximum of 40 wires with diameters in the 1.1-to-1.4-mm range and a maximum width of $23 \mathrm{~mm}$. Their keystone angles are small. The insulation thickness is set to $0.2 \mathrm{~mm}$ per conductor side. The overall diameter of the magnet stays within $900 \mathrm{~mm}$. The quench current is as high as $32 \mathrm{kA}$. The maximum compressive stresses on the midplane of the inner (respectively, outer) layer is $\sim 40 \mathrm{MPa}$ (respectively, $\sim 130 \mathrm{MPa}$ ), while the horizontal force reaches $8 \mathrm{MN}$ per quadrant. The stored energy is circa $900 \mathrm{~kJ} / \mathrm{m}$, leading to an axial force of $0.9 \mathrm{MN}$.

\section{CONCLUSION}

The NED JRA offers a unique opportunity to foster highfield, $\mathrm{Nb}_{3} \mathrm{Sn}$ accelerator magnet development in Europe, by integrating the efforts of major research institutes and calling for a strong industrial involvement. It is very likely, that the Phase I of the Program, devoted mainly to conductor and insulation development, will be fully funded over a 3-year period. No decision has been taken yet regarding the Phase II of the Program, which concerns the manufacturing of a large-bore, high-field dipole magnet model. Preliminary studies based on a scale-up of the MFRESCA design have shown that fields close to $15 \mathrm{~T}$ can be achieved at $4.2 \mathrm{~K}$ in a $88-\mathrm{mm}$ aperture.

\section{ACKNOWLEDGMENT}

The authors wish to thank R. Aleksan for his warm support and defense of the NED proposal.

\section{REFERENCES}

[1] L. Rossi, Superconducting Magnets for the LHC Main Lattice.

[2] D. Leroy and L. Oberli et al., "Design features and performance of a 10 T twin aperture model dipole for LHC," in Proc. of 15th International Conference on Magnet Technology, L. Lianghzhen, S. Guoliao, and Y. Lugang, Eds., Beijing, China, 1998, pp. 119-122.

[3] D. Leroy and G. Spigo et al., "Design and manufacture of a large-bore 10-T superconducting dipole for the CERN cable test facility," IEEE Trans. Appl. Supercond., vol. 10, no. 1, pp. 178-182, March 2000.

[4] A. Gurevich and S. Patniak et al., "Very high upper critical fields in $\mathrm{MgB}_{2}$ produced by impurity scattering," Cond. Mat.

[5] P. J. Lee and D. Larbalestier, "Advances in superconducting strands for accelerator magnet application," in Proc. of the 2003 Particle Accelerator Conference, Portland, Or, May 12-16, 2003.

[6] J. W. Ekin, "Strain effects in superconducting compounds," Adv. Cryo. Eng. (Materials), vol. 30, pp. 823-836, 1984.

[7] K. Okuno, Progress in the Superconducting Magnet Technology Through the ITER CS Model Coil Programme.

[8] P. Libeyre, Mechanical Tests of the ITER Toroidal Field Model Coil.
[9] R. M. Scanlan, D. R. Dietderich, and S. A. Gourlay, "A new generation $\mathrm{Nb}_{3} \mathrm{Sn}$ wire, and the prospects for its use in particle accelerators," in Proc. of the CEC/ICMC 2003 Conference, Anchorage, Al, September 22-26, 2003.

[10] A. D. McInturff and R. Benjegerdes et al., "Test results for a high field (13 T) $\mathrm{Nb}_{3} \mathrm{Sn}$ dipole," in Proc. of 1997 Particle Accelerator Conference, 1998, pp. 3212-3214.

[11] R. Benjegerdes and P. Bish et al., "Fabrication and test results of a high field, $\mathrm{Nb}_{3} \mathrm{Sn}$ superconducting racetrack dipole magnet," in Proc. of the 2001 Particle Accelerator Conference, 2001, pp. 208-210.

[12] S. A. Gourlay, High Field Magnet R\&D in the USA

[13] A. Devred, "High field accelerator magnets beyond LHC," in Proc. of the 2003 Particle Accelerator Conference, Portland, Or, May 12-16, 2003.

[14] J. Strait and M. Lamm et al., "Toward a new LHC interaction region design for a luminosity upgrade," in Proc. of the 2003 Particle Accelerator Conference, Portland, Or, May 12-16, 2003.

[15] J. Perot, "Construction and test of a synchrotron dipole model using $\mathrm{Nb}_{3}$ Sn cable," IEEE Trans. Magn., vol. MAG-19, no. 3, pp. 1378-1380, 1983.

[16] A. Asner and C. Becquet et al., "Development and successful testing of the first $\mathrm{Nb}_{3} \mathrm{Sn}$ wound, in situ-reacted, high-field superconducting quadrupole of CERN," IEEE Trans. Magn., vol. MAG-19, no. 3, pp. 1410-1416, 1983.

[17] A. Asner and R. Perin et al., "First $\mathrm{Nb}_{3} \mathrm{Sn}, 1 \mathrm{~m}$ long superconducting dipole model magnets for LHC break the 10 tesla field threshold," in Proc. of 11th International Conference on Magnet Technology, T. Sekiguchi and S. Shimamoto, Eds., London, UK, 1990, pp. 36-41.

[18] L. Oberli, private communication, 1990.

[19] E. M. Hornsweld and J. D. Elen et al., "Development of ECN-type niobium tin wire toward smaller filament size," Adv. Cryo. Eng. (Materials), vol. 34, pp. 493-498, 1987.

[20] A. den Ouden and S. Wessel et al., "Application of $\mathrm{Nb}_{3} \mathrm{Sn}$ superconductors in high field accelerator magnets," IEEE Trans. Appl. Supercond., vol. 7, no. 2, pp. 733-738, June 1997.

[21] A. den Ouden and H. H. J. ten Kate et al., "Quench characteristics of the $11 \mathrm{~T} \mathrm{Nb}_{3} \mathrm{Sn}$ model dipole magnet MSUT," in Proc. of 15th International Conference on Magnet Technology, L. Liangzhen, S. Guolia, and Y. Luguang, Eds., Beijing, China, 1998, pp. 339-342.

[22] G. Ambrosio, G. Bellomo, and L. Rossi, "A $300 \mathrm{~T} / \mathrm{m} \mathrm{Nb}_{3}$ Sn quadrupole for the low $\beta$ insertions of the LHC," in Proc. of 5th European Particle Accelerator Conference, 1996, pp. 2290-2292.

[23] M. Pojer, private communication, 1999.

[24] J. L. H. Lindenhovius and E. M. Hornsveld et al., "Powder-in-tube (PIT) $\mathrm{Nb}_{3} \mathrm{Sn}$ conductors for high field magnets," IEEE Trans. Appl. Supercond., vol. 10, no. 1, pp. 975-978, March 2000.

[25] M. Durante and P. Bredy et al., "Development of a $\mathrm{Nb}_{3} \mathrm{Sn}$ multifilamentary wire for accelerator magnet applications," Physica $C$, vol. 354 , pp. 449-453, 2001

[26] A. den Ouden and H. H. J. ten Kate et al., "A $10 \mathrm{~T} \mathrm{Nb}_{3} \mathrm{Sn}$ model separator dipole magnet for the CERN LHC," in Proc. of 15th International Conference on Magnet Technology, L. Liangzhen, S. Guolia, and Y. Luguang, Eds., Beijing, China, 1998, pp. 137-140.

[27] R. Ostojic, Superconducting Magnets for the LHC Insertions.

[28] A. den Ouden and W. A. J. Wessel et al., "Conductor related design considerations for a 1 meter $10 \mathrm{~T} \mathrm{Nb}_{3} \mathrm{Sn}$ dipole magnet," IEEE Trans. Appl. Supercond., vol. 13, no. 2, pp. 1288-1291, June 2003.

[29] A. Devred and M. Durante et al., "Development of $\mathrm{Nb}_{3} \mathrm{Sn}$ quadrupole magnet model," IEEE Trans. Appl. Supercond., vol. 11, no. 2, pp. 2184-2187, June 2001.

[30] M. Durante and A. Devred et al., Development and Manufacturing of a $\mathrm{Nb}_{3} \mathrm{Sn}$ Quadrupole Magnet Model at CEA/Saclay for TESLA Interaction Region.

[31] A. Devred, "Insulations systems for $\mathrm{Nb}_{3} \mathrm{Sn}$ accelerator magnet coils manufactured by the wind \& react technique," IEEE Trans. Appl. Supercond., vol. 12, no. 1, pp. 1232-1237, March 2002.

[32] M. Canali and L. Rossi, "DYNQUE, Computer Code for Quench Simulation in Adiabatic Multicoil Superconducting Solenoids,", INFN Internal Report INFN/TC-93/06, June 9, 1993.

[33] C. Meuris and B. Baudouy et al., "Heat transfer in electrical insulation of LHC cables cooled with superfluid helium," Cryogenics, vol. 39, pp. 921-931, 1999.

[34] S. Russenschuck, Ed., "ROXIE: Routine for the Optimization of Magnet X-Sections, Inverse Field Calculation and Coil End Design,”, CERN Internal Report CERN 99-01, April 12, 1999. 